\title{
The epidemiology and socio-economic impact of Rift Valley fever epidemics in Tanzania: A review
}

\author{
Authors: \\ Calvin Sindato ${ }^{1}$ \\ Esron Karimuribo ${ }^{2}$ \\ E.G. Mboera ${ }^{3}$ \\ Affiliations: \\ ${ }^{1}$ National Institute for \\ Medical Research, Tabora, \\ Tanzania \\ ${ }^{2}$ Sokoine University of \\ Agriculture, Tanzania \\ ${ }^{3}$ National Institute for \\ Medical Research, Dar es \\ Salaam, Tanzania \\ Correspondence to: \\ Calvin Sindato \\ Email: \\ kndato@yahoo.co.uk \\ Postal address: \\ PO Box 482, Tabora, Tanzania \\ How to cite this abstract: \\ Sindato, C., Karimuribo, \\ E. \& Mboera, E.G., 2012 \\ 'The epidemiology and \\ socio-economic impact of \\ Rift Valley fever epidemics \\ in Tanzania: A review', \\ Onderstepoort Journal of \\ Veterinary Research 79(2), \\ Art. \#467, 1 page. http:// \\ dx.doi.org/10.4102/ojvr. \\ v79i2.467 \\ Note: \\ Proceedings of the \\ Conference of the Southern \\ African Centre for Infectious \\ Disease Surveillance 'One \\ Health' held at the National \\ Institute for Communicable \\ Diseases, Johannesburg, July \\ 2011.
}

A review was conducted to provide comprehensive update on Rift Valley fever (RVF) in Tanzania, with particular attention devoted to trend of occurrence, epidemiological factors, socio-economic impact and measures which were applied to its control. Information presented in this paper was obtained through extensive literature review. Rift Valley fever was documented for the first time in Tanzania in 1977. This was followed by epidemics in 1997 and 2007. Contrary to the latest epidemic in 2007 sporadic cases of RVF during the previous epidemics were confined to mainly livestock and mostly affecting northern parts of Tanzania. The latest disease epidemic expanded to cover wider areas (mostly northern and central zones) of the country involving both human and domestic ruminants. During the latest disease outbreak $52.4 \%(n=21)$ of regions in Tanzania mainland were affected and majority $(72.7, n=11)$ of the regions had concurrent infections in human and animals.

Phylogenetic comparison of nucleotide and amimo acid sequences revealed different virus strains between Kenya and Tanzania.

Epidemiological factors that were considered responsible for the previous RVF epidemics in Tanzania included farming systems, climatic factors, vector activities and presence of large population of ruminant species, animal movements and food consumption habits. Majority of the RVF positive cases in the latest epidemic were livestock under pastoral and agro-pastoral farming systems.

The disease caused serious effects on rural people's food security and household nutrition and on direct and indirect losses to livestock producers in the country. Psycho-social distress that communities went through was enormous, which involved the thinking about the loss of their family members and/or relatives, their livestock and crop production. Socially, the status of most livestock producers was eroded in their communities.

Cessation of lucrative trade in ruminants resulted in serious economic losses to the populations who were totally dependent upon this income. Livestock internal market flows drastically dropped by $37 \%$ during latest epidemic. Rift Valley fever epidemics had dramatic impact of RVF outbreak on the international animal trade in which there was a $54 \%$ decline in exports equivalent to loss of $\$ 352750.00$. The estimate of loss as a result of deaths for cattle was $\$ 4243250.00$ whereas that of goats and sheep was \$2 202467.00 .

Steps taken to combat epidemics included restriction of animal movements, ban of the slaughter of cattle and vaccination of livestock and health education.

From past epidemics we have learnt that each subsequent outbreak had expanded to cover wider areas of the country. The disease had dramatic socio-economic impacts both at community and nation at large. The main challenges related to the control of RVF outbreaks included lack of preparedness plan for RVF, poor coordination and information transmission, limited facilities and manpower for RVF outbreak intervention. Control of the 2007 RVF epidemic was largely the result of animal and human health agencies working in an integrated manner.
C 2012. The Authors. Licensee: AOSIS OpenJournals. This work is licensed under the Creative Commons Attribution License. 